\title{
Rostain Stéphen, Amazonie, Les 12 travaux des civilisations précolombiennesAmazonie, Les 12 travaux des civilisations précolombiennes
}

Paris, Belin, 2016, 334 p.

\section{Nicola Todorov}

\section{OpenEdition}

\section{Journals}

Édition électronique

URL : https://journals.openedition.org/geohist/1433

DOI : 10.4000/geohist.1433

ISSN : 2264-2617

Éditeur

Association française de la Revue de géographie historique

Référence électronique

Nicola Todorov, « Rostain Stéphen, Amazonie, Les 12 travaux des civilisations

précolombiennesAmazonie, Les 12 travaux des civilisations précolombiennes », Revue de géographie historique [En ligne], Comptes-rendus, mis en ligne le 20 novembre 2016, consulté le 12 juin 2021.

URL : http://journals.openedition.org/geohist/1433 ; DOI : https://doi.org/10.4000/geohist.1433

Ce document a été généré automatiquement le 12 juin 2021.

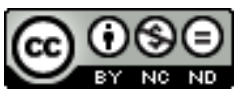

Ce(tte) œuvre est mise à disposition selon les termes de la Licence Creative Commons Attribution -

Pas d'Utilisation Commerciale - Pas de Modification 4.0 International. 


\title{
Rostain Stéphen, Amazonie, Les 12 travaux des civilisations précolombiennesAmazonie, Les 12 travaux des civilisations précolombiennes
}

Paris, Belin, 2016, 334 p.

\author{
Nicola Todorov
}

\section{RÉFÉRENCE}

Rostain Stéphen, Amazonie, Les 12 travaux des civilisations précolombiennes, Paris, Belin, 2016, 334 p.

1 Depuis une quarantaine d'années, l'idée d'une Amazonie précolombienne « vierge » est mise en cause par des chercheurs de disciplines différentes, mais surtout des archéologues, non sans provoquer des débats, parfois extrêmement passionnés. Loin d'être «vide" d'hommes, cette forêt aurait été beaucoup plus peuplée qu'on ne le pensait et surtout aménagé de manières très variées et donc modifiée par les populations que les conquérants européens ont appelées indiennes.

2 Avec ce livre, Stéphen Rostain, le premier archéologue français à s'être spécialisé dans la période précolombienne de l'Amazonie, nous fournit une synthèse de plusieurs décennies de travaux archéologiques. Soucieux de mettre en valeur les achèvements des civilisations amazoniennes avant 1492, l'auteur dresse un parallèle avec ceux de la civilisation grecque telle qu'elle apparait à la lecture du mythe d'Hercule et de ses 12 travaux. L'ouvrage a par conséquent 12 chapitres donc chacun établit une comparaison entre un aspect des sociétés précolombiennes et le monde grecque (archaïque) selon la mythologie. Le combat contre le taureau de Minos, symbolisant la domestication, est 
ainsi comparé à la domestication, notamment des plantes, en Amazonie; le nettoyage des écuries d'Augias, que Hercule accomplit en dérivant les fleuves Alphée et Pénée vers ces écuries sales, qu'il laissa sécher ensuite, est mis en parallèle avec l'assèchement des terres basses par la technique des champs surélevés, étudiée par l'auteur, notamment sur la côte des Guyanes.

3 Les échanges à longue distance entre les populations précolombiennes d'Amazonie supporteraient facilement la comparaison avec le périple qu'impliquait la tâche d'Hercule de ramener le troupeau de Géryon d'Erythie. Dans l'ensemble, l'auteur défend les thèses d'une Amazonie beaucoup plus densément peuplée avant la conquête par les Européens, telles qu'elles sont mises en avant par un certain nombre de chercheurs, comme Michael Heckenberger ou William Denevan et appuyées entre autres sur l'étendue des « terres noires » d'origine anthropique les terras pretas.

4 La majeure partie du continent, croyait-on, n'avait qu'un peuplement claire-semé, fait de tribus de chasseurs et de cueilleurs. Une explication étrange, du point de vue d'un géographe, se serait maintenue parmi les archéologues jusqu'aux années 1960 pour rendre compte de ce contraste entre les terres basses amazoniennes et les civilisations andines: le milieu amazonien aurait été tellement contraignant que de grandes sociétés structurées avec un Etat n'auraient pas pu s'y constituer. L'auteur critique ce «déterminisme écologique», débattu, rejeté, revisité, par les géographes depuis longtemps. Selon Stéphen Rostain, le milieu amazonien a vu se développer des sociétés complexes, ayant fait preuve d'une grande inventivité pour modifier l'environnement. La forêt vierge serait un mythe né de la perception d'une sylve qui se serait développée à la suite de l'effondrement démographique, provoqué par le choc microbien.

5 Ne passons pas sous silence que ces conclusions sont contestées par un certain nombre d'écologues et paléo-environnementalistes. Un certain nombre d'idées et de concepts proposés par la géohistoire mériteraient aussi d'être appliqués et testés au regard de la validité de cette théorie d'une Amazonie profondément anthropisée avant le premier contact avec l'Ancien Monde. Comment se fait-il qu'à l'échelle du continent, les grands foyers de peuplement amérindiens précolombiens, celui des Andes (Incas) et du haut plateau du Mexique (Aztèques), concentrent toujours l'essentiel des populations amérindiennes aujourd'hui et ont donc pu se reconstituer, après le déclin démographique indéniable consécutif à la conquête, alors que le bassin de l'Amazone si densément peuplé au début du XVIe siècle, comme le postulent certains, n'a pas pu se régénérer ? Même si l'Amazonie était moins densément peuplée que les foyers de civilisations de montagne, mais davantage qu'on ne le pensait, pourquoi cet écart entre leurs poids démographique relatifs aujourd'hui ? L'étude de la géographie historique du peuplement et son évolution différenciée après 1492 serait ici certainement riche d'enseignements.

6 L'ouvrage est richement illustré avec de nombreuses photographies prises par l'auteur, mais aussi avec une iconographie produite par les Européens conquérants, et témoigne de la grande érudition de l'auteur et de l'étendue de ses travaux de terrain. 